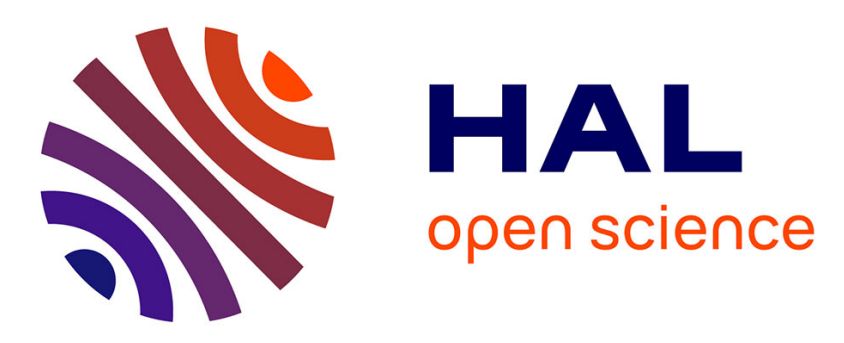

\title{
Enhancement of bending properties of Douglas-fir and poplar laminate veneer lumber (LVL) beams with carbon and basalt fibers reinforcement
}

Francisco J. Rescalvo, Robin Duriot, Guillaume Pot, Antolino Gallego, Louis Denaud

\section{To cite this version:}

Francisco J. Rescalvo, Robin Duriot, Guillaume Pot, Antolino Gallego, Louis Denaud. Enhancement of bending properties of Douglas-fir and poplar laminate veneer lumber (LVL) beams with carbon and basalt fibers reinforcement. Construction and Building Materials, 2020, 263, pp.120185. 10.1016/j.conbuildmat.2020.120185 . hal-02958313

\section{HAL Id: hal-02958313 https://hal.science/hal-02958313}

Submitted on 5 Oct 2020

HAL is a multi-disciplinary open access archive for the deposit and dissemination of scientific research documents, whether they are published or not. The documents may come from teaching and research institutions in France or abroad, or from public or private research centers.
L'archive ouverte pluridisciplinaire HAL, est destinée au dépôt et à la diffusion de documents scientifiques de niveau recherche, publiés ou non, émanant des établissements d'enseignement et de recherche français ou étrangers, des laboratoires publics ou privés. 


\title{
Enhancement of bending properties of Douglas-fir and poplar laminate veneer lumber (LVL) beams with carbon and basalt fibers reinforcement
}

\author{
Francisco J. Rescalvo ${ }^{a^{*}}$, Robin Duriot ${ }^{\mathrm{b}}$, Guillaume Pot $^{\mathrm{b}}$, Antolino Gallego ${ }^{\mathrm{a}}$, Louis \\ Denaud $^{b}$
}

${ }^{a}$ Building Engineering School. University of Granada. Campus de Fuentenueva s/n. 18071. Granada, Spain. rescalvo@ugr.es

b Arts et Metiers Institute of Technology, LABOMAP, HESAM Université, F-71250 Cluny, France.

\section{* Corresponding author}

\begin{abstract}
This paper presents the experimental results of the bending mechanical behavior (static and dynamic moduli, and maximum stress) of LVL (Laminated Veneer Lumber) beams reinforced with fiber polymer material (FRP). Different variables were studied: i) Wood species (Douglas fir or poplar); ii) Type of reinforcement (bidirectional carbon, unidirectional carbon or basalt); iii) Veneer quality and iv) Veneers orientation in the beam (flatwise or edgewise). The reinforcement percentages respect to the total cross-section was of $2.17 \%, 0.89 \%$ and $1.74 \%$ for the unidirectional carbon, bidirectional carbon and basalt, respectively. A clear improvement provided by unidirectional carbon has been demonstrated (up to $40 \%$ more in the elastic modulus for the flatwise layout and more than $20 \%$ of the maximum stress, for both wood species). The influence of the quality of the veneers of the panel was also clearly demonstrated: the weakest wood material obtained the greatest improvements in their mechanical properties when reinforced, allowing to obtain stiff second quality poplar LVL, or strong second quality Douglas fir LVL.
\end{abstract}

Key-words: Wood, composites, Douglas-Fir, Poplar, LVL, retrofitting

\section{Introduction}

The building, understood as the use of buildings, the production and transport of materials, construction, maintenance and the end of the useful life of construction systems, represents up to $36 \%$ of the greenhouse gas emissions of the European Union [1]. Throughout the twentieth century, reinforced concrete has allowed a competitive and rapid development of our built environment. Today we know that an average reduction of $2.1 \mathrm{t}$ of $\mathrm{CO}_{2}$ emissions can be achieved substituting $1 \mathrm{t}$ of concrete by $1 \mathrm{t}$ of wood in the building process. [1]. Wood, a building material widely spread on our planet is renewable and biologically based. Compared to other materials, it has environmental advantages in all its phases. Wood also has certain limitations with respect to other materials, such as its durability, fire resistance or lack of homogeneity, among others. However, there is a growing social interest for a construction with less environmental impact. Likewise, the growing awareness in the sector is evident by reducing its carbon footprint and its ecological backpack, being the 
use of wood, in combination with other materials widely validated through hybrid solutions, one of the most effective and profitable strategies in hands of the architects and prescribers of the sector. The growing social interest in a construction of almost zero energy consumption and the numerous added values of wood, are a great opportunity for this material in the construction sector, which is a huge opportunity for many tree species such as planted poplar of development based on technological products.

Wood can contribute to the market with technological products that respond to the current needs of construction, and thus revalue poplar plantations and establish a processing industry in the area with added value and sustainability over time, much greater than the current poplar wood processing industry. New technologies and scientific advances offer poplars the possibility of moving from traditional products (paper, chipboard panels, biomass, pallets, furniture, plywood, fruit boxes, etc.) to technological products of high added value in wood construction (Oriented Strand Board panels, I beams, trusses, Cross Laminated Timber wood, high quality structural plywood panels, or Laminated Veneer Lumber (LVL) wood, among others).

LVL is made of several wood veneers bound together, where for standard LVL all are placed in grain direction. Although less used, it can be found crossbanded LVL which has veneers in the perpendicular grain direction. LVL is used in many structural applications because of its high mechanical properties [2]. The modulus of rupture in bending (MOR) of LVL is higher than solid wood with less variations because of the even distribution of natural defects such as knots, slope of grain or splits [3]. In general, LVL is manufactured by using secondary qualities (i.e. presence of many knots, lower density and mechanical properties). LVL can be made of very different wood species, such as beech, birch, poplar, spruce, Douglas fir, etc.. The effects of ply organization on the mechanical properties of LVL elements have been studied, demonstrating that poplar and beech LVL beams offer higher bending strength and modulus of elasticity (MoE) compared to solid elements [4,5]. Some authors found that a first-grade veneer LVL beam can have a bending strength improvement of $6 \%$ respect to LVL beams manufactered with second or third-grade veneers [6]. Other authors found, by grading beech veneers thanks to the measurement of fiber orientation, that the difference in MoE can reach 29\% [7]. Meanwhile, the width of the layers used for the lamination process does not affect the flexural behavior and MoE of LVL elements [8,9], defects such as knots, their diameter and the distance between them decrease the mechanical properties of the LVL beams [10, 11]. By testing secondary quality beech LVL [10] obtained mean bending strength of $63 \mathrm{MPa}$ while beech LVL could reach more than twice this value if there was no defect in it [4].

In order to overcome the lower mechanical properties of second quality wood with presence of many knots, lower and more scattered mechanical properties, the combination of wood with fiber reinforced plastics materials (FRP) has been discussed in numerous research papers from the early 1960s [12,13]. [14] focuses on the use of this type of material on LVL elements, studying its economic feasibility by using Eglass, S-glass and Kevlar-49 as reinforcing material, asserting the enhancement of the longitudinal strength and stiffness when unidirectional reinforcement is used. Furthermore, previous works have demonstrated the importance of the quality of the wood used in laminated lumber under bending stresses [15]. The use of carbon and basalt fiber reinforced polymers (CFRP and BFRP, respectively) has been studied in sawn wood and technological products such as glulam and LVL elements, demonstrating the improvement of mechanical properties under different reinforcement configurations [16-25]. 
In this paper, Douglas fir and poplar LVL beams have been manufactured and tested in edgewise position and flatwise and edgewise positions, respectively. The enhancement of the CFRP reinforcement was firstly evaluated in Douglas fir LVL beams, gluing the reinforcing material at the external faces of the beams. After this evaluation, a more complex manufacturing process was carried out, embedding the reinforcement in poplar LVL beams and comparing different types of FRP in order to evaluate the enhancement of the mechanical properties and its commercial feasibility comparing carbon and basalt, which is about $1 / 3$ cheaper than carbon based materials. In addition, the effect of the use of two qualities of veneer has been evaluated.

\section{Materials and Methods}

\subsection{FRP properties}

Carbon and basalt based reinforced fibers (CFRP and BFRP, respectively) were used as reinforcing material. In edgewise bending, the lateral reinforcement may prevent shear failure in wood, and it is expected that bidirectional layout is more resistant to shear than unidirectional, this is why two types of CFRP were compared, unidirectional CFRP Mapewrap ${ }^{\circledR}$ C-Uni-Ax and bidirectional CFRP Mapewrap® C-BiAx. For the case of basalt, the unidirectional Mapewrap $\AA$ B Uni-Ax was used, in order to compare basalt and carbon unidirectional. For the CFRP-wood adhesion, the epoxy resin Mapewrap $\AA 21$ was used, ensuring a moisture content of $10 \pm 2 \%$ of the wood during the manufacturing process. Table 1 summarizes the main properties of the three types of used commercial FRPs.

\section{MAPEWRAP C UNI- MAPEWRAP C BI- MAPEWRAP B UNI-} AX AX AX

\begin{tabular}{cccc}
\hline Type of FRP & Carbon & Carbon & Basalt \\
Fiber orientation & Unidirectional & Bidirectional [0/90] & Unidirectional \\
Specific weight $\left(\mathbf{g} / \mathbf{m}^{2}\right)$ & 300 & 238 & 400 \\
Thickness $(\mathbf{m m})$ & 0,166 & 0,064 & 0,140 \\
$\begin{array}{c}\text { Resistant area per width } \\
\text { unit }\left(\mathbf{m m}^{2} / \mathbf{m m}\right)\end{array}$ & 166,6 & 64,2 & 142,5 \\
$\begin{array}{c}\text { Max. tensile stress }(\mathbf{M P a}) \\
\text { Tensile elastic } \mathbf{m o d u l u s} \\
\mathbf{( G P a )}\end{array}$ & 4830 & 4800 & 4840 \\
Max. elongation (\%) & 230 & 230 & 89 \\
\hline
\end{tabular}

Table 1. Main properties of the FRPs.

\subsection{Douglas LVL samples}

The Douglas fir used in this study came from Correze, a French department located in the western part of Massif Central, which is one of the main reserves of this species in France. The peeled logs were representative of the Douglas fir that can be supplied in this region, this Douglas fir having large growth rings and large knots in comparison with spruce (which is the main softwood species used in Europe to produce LVL). The veneers obtained were visually knotty. All bolts were soaked in hot water at $50 \pm 2{ }^{\circ} \mathrm{C}$ for 48 hours before peeling. Afterward, bolts were cut into veneers using an industrial 
rotary peeling lathe. The thickness of each veneer was set to $3 \mathrm{~mm}$. In Douglas fir, the color is highly differentiated between heartwood (salmon pink) and sapwood (white cream, yellow) and allows for visual sorting. The veneers from the middle class containing too much sapwood were thus discarded. Only purely heartwood was kept for the present study. Then, the veneers were dried using an industrial air drying machine to reduce veneers moisture content to $6 \% \mathrm{MC}$. The dimensions of each veneer were $2600 \mathrm{~mm} \times 1300 \mathrm{~mm} \times 3 \mathrm{~mm}$.

The veneers were glued together with the grain orientated parallel to panel length. The glue used was a thermosetting phenplast resin or phenolic glue, with glue spread of $190 \mathrm{~g} / \mathrm{m}^{2}$. Then, the glued veneers were pressed under between 1 and $1,1 \mathrm{MPa}$ for about 30 minutes in a stage press at $200^{\circ} \mathrm{C}$. After gluing and pressing, the LVL were stacked and stabilized for three days before cutting in several $120 \mathrm{~mm}$ beams. Among several beams representative of the different panels, smaller $850 \mathrm{~mm} \times 45 \mathrm{~mm} \times$ $45 \mathrm{~mm}$ beams were cut out as Figure 1 shows with a specific nomenclature for each particular beam extracted (Table 1).
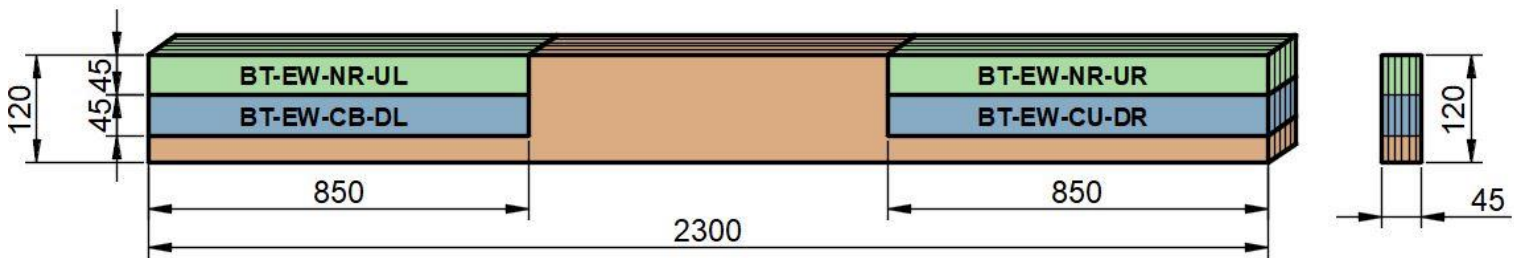

Figure 1. Sampling Douglas specimens scheme (non-representative number of plies). Distances in $\mathrm{mm}$

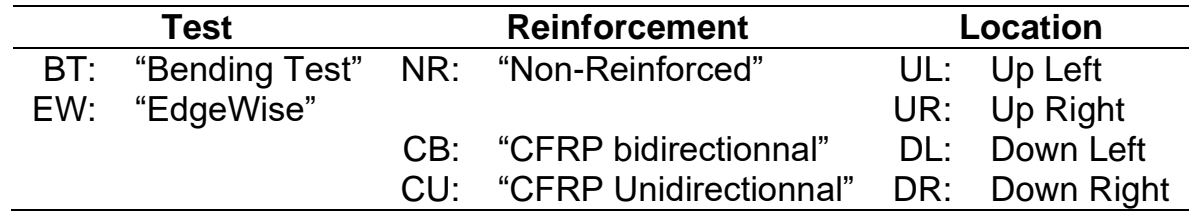

Table 1. Douglas specimens designations.

All the beams were always taken cut by couple of beams, taken from the location showed in Figure 1. Locating the cut-outs of the daughter beams is mainly justified by the following reason: the material provides better integrity at the ends, away from the predominantly central fracture area and in the upper part of the mother beams. The number of beams and different testing conditions are summarized in Table 2. In particular, the right couples of beams were used to quantify the effect of unidirectional CFRP while the left couples of beams were used to quantify the effect of bidirectional CFRP. Indeed, a layer of FRP was glued to one beam from each couple, with epoxy resin during 24 hours at room temperature (Figure 2).

I) 15 veneers

II) 2 FRP plies

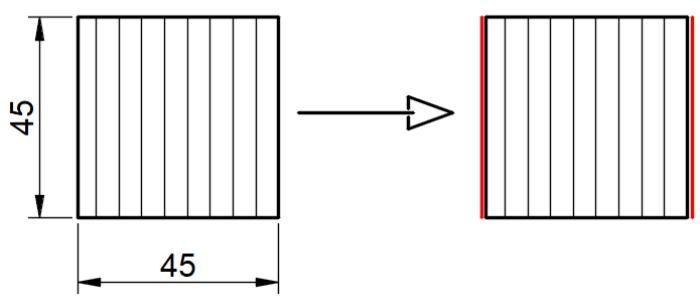

Figure 2. Elaboration process of the reinforced Douglas fir LVL beams. Distances in $\mathrm{mm}$. 


\begin{tabular}{|c|c|c|c|c|c|}
\hline $\begin{array}{l}\text { Wood } \\
\text { Species / } \\
\text { source }\end{array}$ & Quality & Type of FRP & $\begin{array}{l}\text { Bending test } \\
\text { orientation }\end{array}$ & Nomenclature & $\begin{array}{c}\text { Number of } \\
\text { samples }\end{array}$ \\
\hline $\begin{array}{l}\text { Douglas fir } \\
\text { heartwood / }\end{array}$ & - & $\begin{array}{c}\text { Non- } \\
\text { reinforced }\end{array}$ & EW & $\begin{array}{c}\text { Doug-NR- } \\
\text { (UR/UL) }\end{array}$ & $18 / 23$ \\
\hline Industrial & - & CFRP-uni & EW & Doug-CU-DR & 18 \\
\hline \multirow[t]{4}{*}{ source } & - & CFRP-bidi & EW & Doug-CB-DL & 23 \\
\hline & \multirow{3}{*}{$\begin{array}{c}\text { Q1 } \\
\text { (high quality) }\end{array}$} & $\begin{array}{l}\text { Non- } \\
\text { reinforced }\end{array}$ & Flatwise (FW) & Pop_NR_Q1 & 13 \\
\hline & & $\begin{array}{l}\text { Non- } \\
\text { reinforced }\end{array}$ & Edgewise (EW) & Pop_NR_Q1 & 13 \\
\hline & & CFRP-uni & FW & Pop_CU_Q1 & 5 \\
\hline Poplar I-214 / & & CFRP-uni & EW & Pop_CU_Q1 & 5 \\
\hline \multirow[t]{6}{*}{ One tree } & & CFRP-uni & FW & Pop_CU_Q2 & 8 \\
\hline & & CFRP-uni & EW & Pop_CU_Q2 & 8 \\
\hline & Q2 & CFRP-bidi & FW & Pop_CB_Q2 & 13 \\
\hline & (low quality) & CFRP-bidi & EW & Pop_CB_Q2 & 13 \\
\hline & & BFRP-uni & FW & Pop_BU_Q2 & 13 \\
\hline & & BFRP-uni & EW & Pop_BU_Q2 & 13 \\
\hline
\end{tabular}

Table 2. Test matrix of LVL beams.

\subsection{Poplar LVL samples}

Poplar wood from the cultivar I-214 was used for LVL manufacturing. All the raw material was extracted from the same tree divided in 6 logs with a log length of 900 $\mathrm{mm}$, in an attempt to avoid as much as possible the heterogeneity of the results during comparisons. However, due to the presence of knots in upper logs, differences in veneer quality were clearly visible (Figure 3). Thus, the veneers obtained from the logs above $2.5 \mathrm{~m}$ from ground were assembled together and called "Q2" quality, while the others (obtained from logs below $2.5 \mathrm{~m}$ ) were called "Q1" quality (better quality).

Veneers with a thickness and length of $3 \mathrm{~mm}$ and $850 \mathrm{~mm}$ were peeled, and then dried in a climate chamber at $30.7{ }^{\circ} \mathrm{C}$ and $70 \%$ of relative humidity during 48 hours. The differences between the two qualities and different size are detailed in Table 3 . The width of the veneers, the amount of adhesive and the distance between adhesive lines varied during the gluing process (Table 3 ). Regardless of the quality of the veneers, the elaboration process was divided in two steps (Figures 4 and 5): I) 13 veneers were glued with the PU adhesive Purbond $\AA$ HB S309, applying a total pressure of 0.5 $\mathrm{N} / \mathrm{mm}^{2}$ at room temperature $\left(20^{\circ} \mathrm{C}\right.$ during 4 hours). II) Application of the three different kinds of FRP and the last 2 veneers of poplar, gluing them with the epoxy resin ensuring constant pressure during 24 hours at room temperature.

Once the panels were cured, 10 and 19 beams were extracted from the Q1 and Q2 panels, respectively. Each beam was prepared with a cross-section of $45 \mathrm{~mm} \times 45 \mathrm{~mm}$ and a total length of $760 \mathrm{~mm}$. To be fair in comparison, due to the two types of bending tests performed (flatwise and edgewise), the beams extracted from each panel were used alternately for each type of bending tests, i.e. the odd beams were used for FW beams and the even beams for EW ones (Figure 6). Table 2 summarizes the samples used in the whole study. 

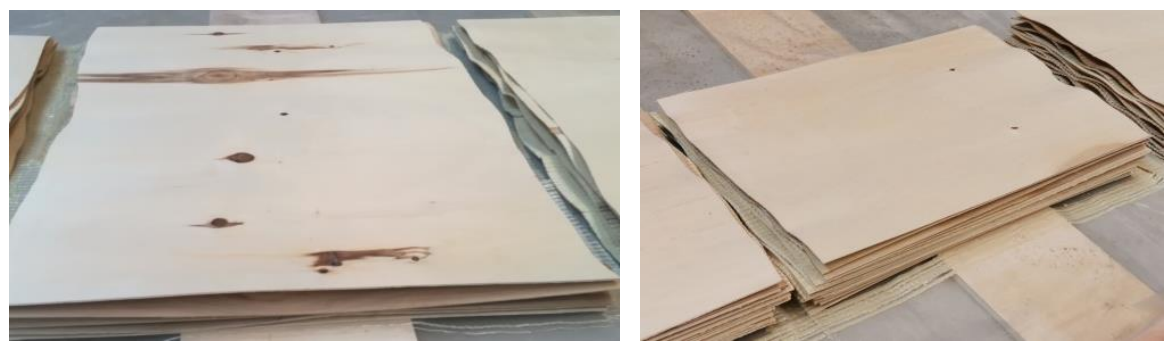

Figure 3. Veneers used in the paneling process. Left: Low quality veneers for Q2 panels. Right: High quality veneers for Q1 panels.

\begin{tabular}{ccc} 
& $\begin{array}{c}\text { Q1 panels } \\
\text { (high quality) }\end{array}$ & $\begin{array}{c}\text { Q2 panels } \\
\text { (low quality) }\end{array}$ \\
\hline Width of the veneer $(\mathbf{m m})$ & 500 & 1000 \\
Amount of adhesive $\left(\mathbf{g} / \mathbf{m}^{2}\right)$ & 200 & 150 \\
Distance between adhesive lines $(\mathbf{m m})$ & 5 & 10 \\
Part of the tree where the veneers come from $(\mathbf{m})$ & $0.5-2.5$ & $2.5-6.1$
\end{tabular}

Table 3. Main characteristics of the two types of poplar panels.

I) 13 veneers

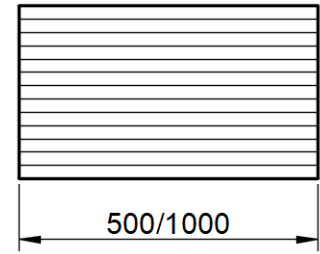

II) 2 FRP plies + 2 external veneers

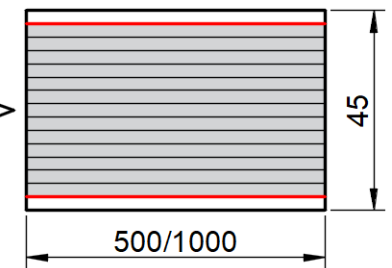

Figure 4. Manufacturing process of the reinforced LVL poplar panels. Distances in $\mathrm{mm}$.

a)

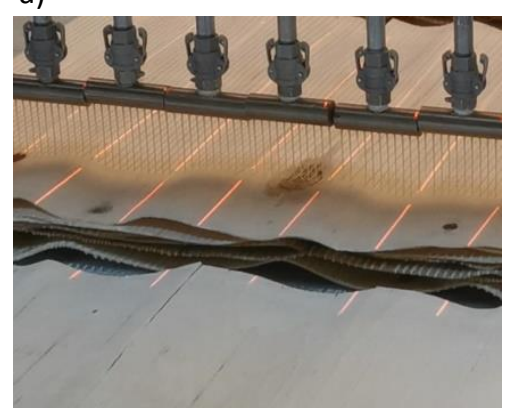

c)

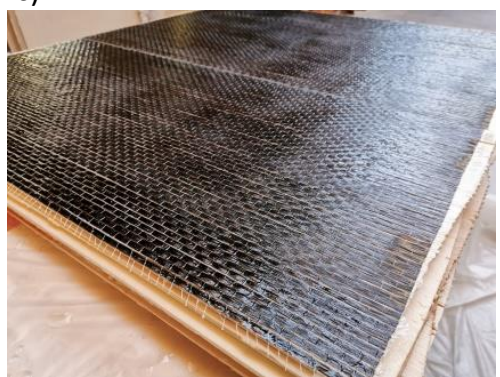

b)

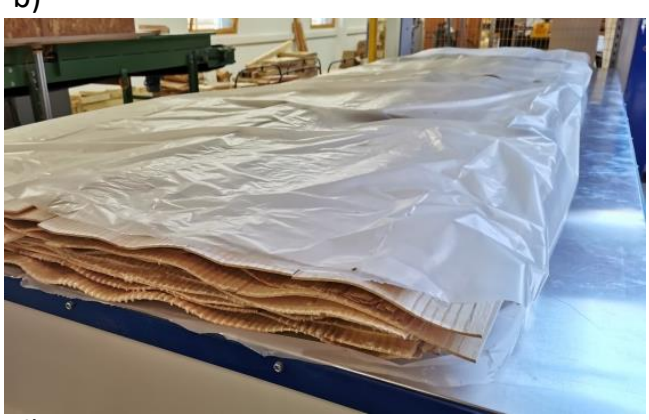

d)

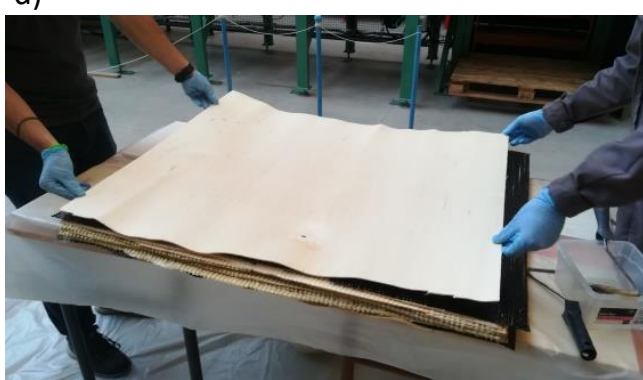

Figure 5. Images of the manufacturing process of the reinforced LVL poplar panels. a) Gluing application. b) Panels ready to be pressed. c) Application of the FRP. d) Placement of the external veneers. 


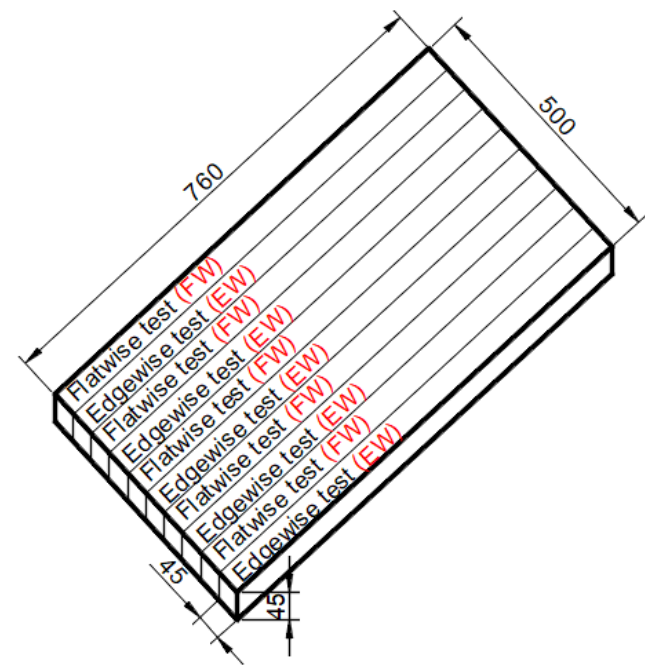

Figure 6. Distribution of flatwise (FW) and edgewise (EW) beams extracted from a $500 \mathrm{~mm}$ width panel. Distances in $\mathrm{mm}$.

\subsection{Vibration test}

[26] showed that the Timoshenko bending theory can be applied to determine the dynamic longitudinal $\mathrm{MoE}$ and the shear modulus from the flexural vibration frequencies in free-free boundary condition. Indeed, they gave the following solution of the equation of motion of a vibrating beam at the first order:

$$
\frac{M O E_{d y n-X W}}{\rho}-\frac{M O E_{d y n-X W}}{K G_{X W}} x_{n}=y_{n}
$$

where $M o E_{d y n-X W}$ is the longitudinal dynamic MoE when bending is in edgewise or flatwise direction, "XW" being replaced by "EW" or "FW", respectively; $\rho$ is the density; $K$ is the shear factor ( $K=5 / 6$ for a rectangular cross-section); $G_{X W}$ is the dynamic shear modulus when bending is in edgewise or flatwise direction, "XW" being replaced by "EW" or "FW", respectively; $x_{n}$ and $y_{n}$ are parameters that depend on the vibrational mode frequency (see [26] for details). By plotting $y_{n}$ against $x_{n}$ for different vibration modes, a linear regression can be performed and the dynamic MoE and shear modulus can be found. The deviation of this equation is generally less than $1 \%$ if the length-todepth ratio is between 10 and 20 (about 19 in the present work). Based on this theory, the BING device (Beam Identification by Non Destructive Grading, [27]) was used to test all the samples in both EW and FW flexural vibrations, and thus obtain $M o E_{d y n-E W}$ and $M o E_{d y n-F W}$.

\subsection{Bending test}

A four-point bending test has been performed on every specimen following the [28] standard, using a distance equal to 810 and $750 \mathrm{~mm}, 18$ and 17 times the specimen's height between the support for Douglas fir and poplar LVL beams, respectively. The distance between a loading point and the nearest support (a) was set as 285 and 255 $\mathrm{mm}$ for Douglas fir and poplar LVL beams, respectively. All the tests were made with a bending machine composed of a $100 \mathrm{kN}$ electric actuator, equipped with a load sensor, and a global deflection rotary potentiometer sensor. The upper and lower supports were made by $4 \mathrm{~cm}$ wide metal plates, fitted on pivot. Figure 8 shows a picture of a particular test. 


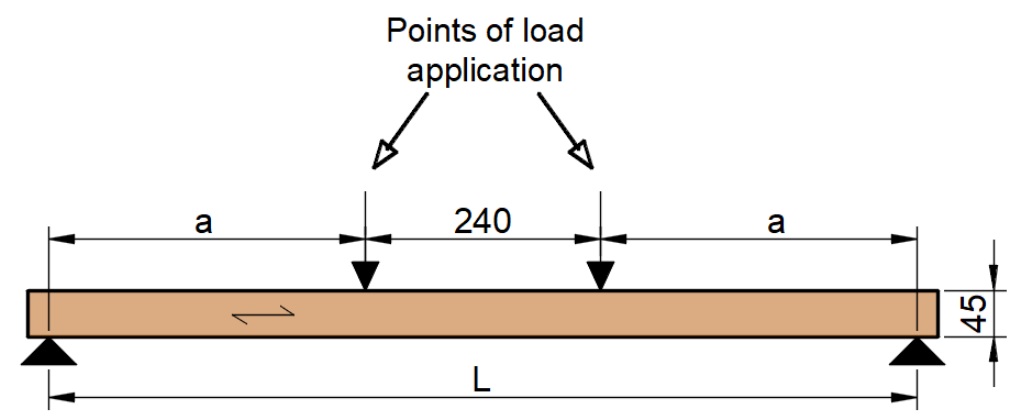

Figure 7. 4-point bending tests configuration for Douglas fir and poplar LVL beams.

Maximum bending stress was calculated according to the Equation 2.

$$
\sigma_{\max }=\frac{a F_{\max } h}{4 I_{G Z}}(2)
$$

where:

- $F_{\text {max }}$ is the maximum bending effort.

- $\quad a$ is the distance between a loading point and the nearest support.

- $h$ is the height of the beam.

- $\mathrm{I}_{\mathrm{Gz}}$ is the moment of inertia for a rectangular cross section beam.

Global MoE was calculated according to the Equation 3.

$$
E_{m, g}=\frac{\left(3 a L^{2}-4 a^{3}\right)\left(F_{2}-F_{1}\right)}{48 I_{G Z}\left(V_{2}-V_{1}\right)}(3)
$$

where:

- $\mathrm{L}$ is the beam length supports $(\mathrm{mm})$

- $\mathrm{V}_{2}-\mathrm{V}_{1}$ is the increment of displacement measured by the rotary potentiometer corresponding to $F_{2^{-}} F_{1}(\mathrm{~mm})$.

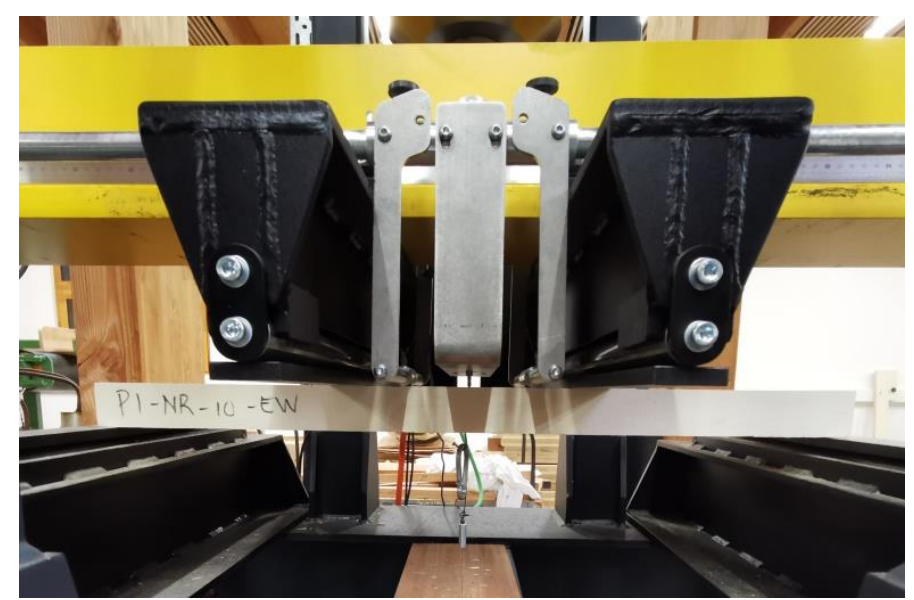

Figure 8. LVL poplar beam during bending test.

\section{Results and Discussion}

This section shows the results obtained in terms of dynamic modulus, MoE $E_{\text {dyn, }}$ global modulus $\mathrm{MoE}_{g, \mathrm{~m}}$, and maximum bending stress. Firstly, for the case of Douglas fir LVL, a comparison was made between the non-reinforced configuration (NR) and unidirectional $(\mathrm{CU})$ and bidirectional $(\mathrm{CB})$ carbon reinforcement configurations. All 
Douglas fir samples were tested in edgewise position. Then, for the case of poplar LVL, results were divided in three groups: Group I, in which a comparison between the nonreinforced (NR) and unidirectional carbon (CU) for the high-quality panel (Q1) was carried out; Group II, in which a comparison of the high-quality panel (Q1) and lowquality panel (Q2) was carried out for the case of unidirectional carbon (CU) reinforcement; Group III, for which a comparison between the non-reinforced (NR), unidirectional carbon (CU) and unidirectional basalt (BU) for the low-quality panel (Q2) is shown. For all the three groups the edgewise and flatwise configurations are shown and compared to each other.

\subsection{Douglas LVL}

Table 4 summarizes the average values of the main mechanical properties of the LVL Douglas fir tested beams in edgewise position. The dynamic modulus ( $\left.\mathrm{MoE}_{\mathrm{dyn}}\right)$, the global modulus $\left(\mathrm{MoE}_{\mathrm{m}, \mathrm{g}}\right)$ and the maximum stress are presented comparing the nonreinforced beams with each type of reinforcement, CU and CB (carbon unidirectional and bidirectional, respectively). Figure 9 depicts the stress-deflection curves for each LVL Douglas fir beams.
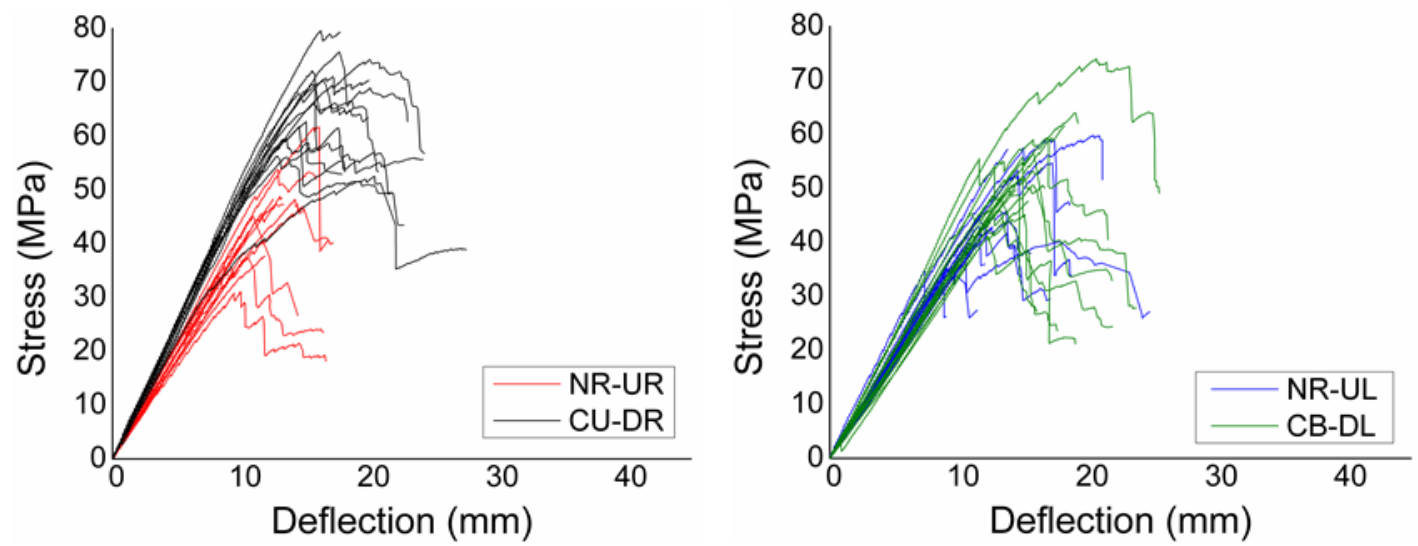

Figure 9. Stress versus global deflection for the LVL Douglas fir tested beams.

\begin{tabular}{cccc}
\hline Reinforcement & MoE $_{\text {dyn }}(\mathbf{G P a}) \pm \mathbf{C O V}$ & $\mathbf{M o E}_{\mathrm{m}, \mathrm{g}}(\mathbf{G P a}) \pm \mathbf{C O V}$ & $\begin{array}{c}\text { Max. Stress } \\
(\mathbf{M P a}) \pm \mathbf{C O V}\end{array}$ \\
\hline NR-UR & $13.1 \pm 6.8 \%$ & $12.1 \pm 7.6 \%$ & $48.9 \pm 20.6 \%$ \\
CU-DR & $15.6 \pm 11.4 \%$ & $14.5 \pm 5.5 \%$ & $69.0 \pm 13.4 \%$ \\
$\begin{array}{c}\text { Var. respect NR-UR } \\
(\%)\end{array}$ & 19.5 & 20.4 & 40.9 \\
NR-UL & $12.3 \pm 11.1 \%$ & $11.8 \pm 9.7 \%$ & $47.7 \pm 19.7 \%$ \\
CB-DL & $12.4 \pm 9.6 \%$ & $11.3 \pm 10.6 \%$ & $55.6 \pm 14.7 \%$ \\
$\begin{array}{c}\text { Var. respect NR-UL } \\
(\%)\end{array}$ & 0.8 & -4.2 & 16.4 \\
\hline
\end{tabular}

Table 4. Main mechanical properties of the LVL Douglas fir beams tested.

It can be clearly seen that the two types of reinforcement behave differently. The unidirectional carbon reinforcement (CU-DR) enhanced all the mechanical properties with remarkable improvements of $19.5 \%, 20.4 \%$ and $40.9 \%$ for the $\mathrm{MoE}_{d y n}, \mathrm{MoE}_{\mathrm{m}, \mathrm{g}}$ and 
maximum stress, respectively. With respect to the bi-directional CFRP, no improvement is obtained, as the values are within the COV. This fact can be associated with the edgewise position and the external application of the CFRP. However, an increase in the maximum stress of $16.4 \%$ was achieved for this type of reinforcement. Regarding the stress-deflection relationship shown in Figure 9, an improvement in the ductile behavior of the reinforced beams can be noted, regardless of the type of CFRP.

\subsection{Poplar LVL}

Beams mainly failed in two patterns, tensile and shear. Figure 10 shows some examples for each failure pattern. NR beams and all reinforced beams tested in edgewise position had a tensile failure. Thus, the maximum EW bending stress could be considered as the maximum bending strength. However, all the beams with FRP tested in flatwise position had shear failure. The reason lies in the fact that the flexural strength contribution of the FRP exceeds the shear strength of the poplar veneer itself, causing this type of failure. Thus, the maximum FW bending stress was not the maximum bending strength, but the bending stress reached when the shear failure occured. This may explain why the maximum FW bending was only slightly higher than maximum EW bending stress. As a result, the shear resistance becomes a key aspect for both the design and a proper application of the reinforcement.

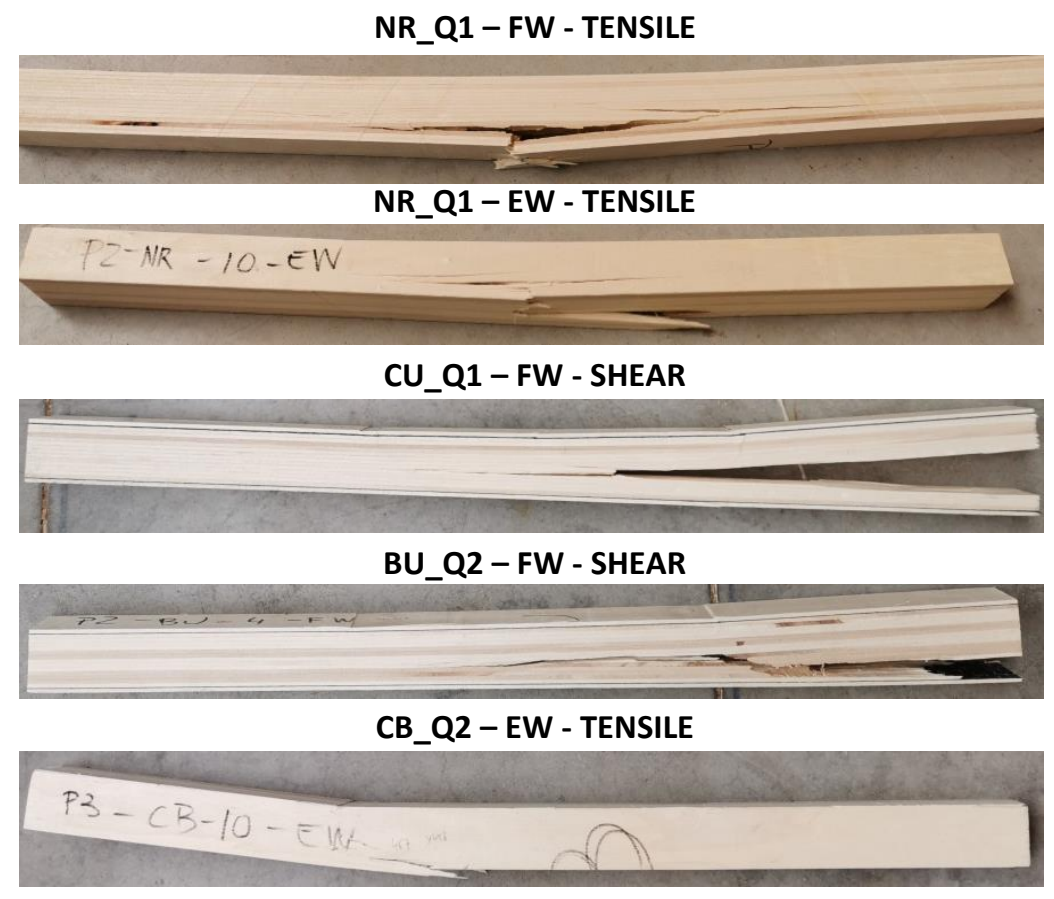

Figure 10. Failure patterns.

Figure 11 depicts a comparison between the dynamic modulus for each beam obtained for flatwise and edgewise position, $\mathrm{MoE}_{\mathrm{dyn}-\mathrm{FW}}$ and $\mathrm{MoE}_{\mathrm{dyn}-\mathrm{EW}}$, respectively. Due to the layup, reinforced LVL was stiffer in flatwise than in edgewise configuration, while it was not the case for non-reinforced LVL. It can be seen the clear influence of the reinforcement of the CU_Q1 beams compared to the non-reinforced. The variation of bending moduli appeared to be much higher for CU-Q1 than CU_Q2 and other types of reinforcements, and the enhancement of the dynamic modulus was higher in flatwise than edgewise configuration. 

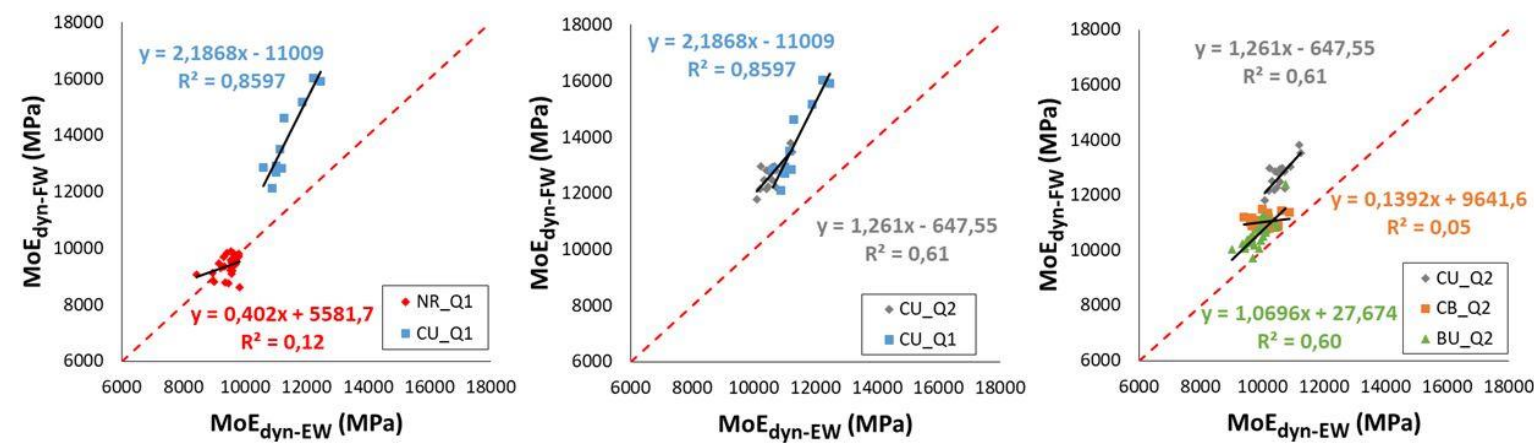

Figure 11. Dynamic modulus for the tested poplar beams: flatwise versus edgewise. Red dotted line: $y=x$ line.

Tables 5, 6 and 7 show the average values of the dynamic elastic modulus (MoE $\mathrm{E}_{\mathrm{dyn}}$ ), global modulus $\left(\mathrm{MoE}_{\mathrm{m}, \mathrm{g}}\right)$ and maximum stress for the beams tested in bending in both flatwise and edgewise configurations. Due to the shear failure mode for the reinforced beams tested in flatwise (Figure 10), it was not possible to determine the real MOR for this particular case. Figure 12 represents the stress versus the global deflection for all the beams in each group.
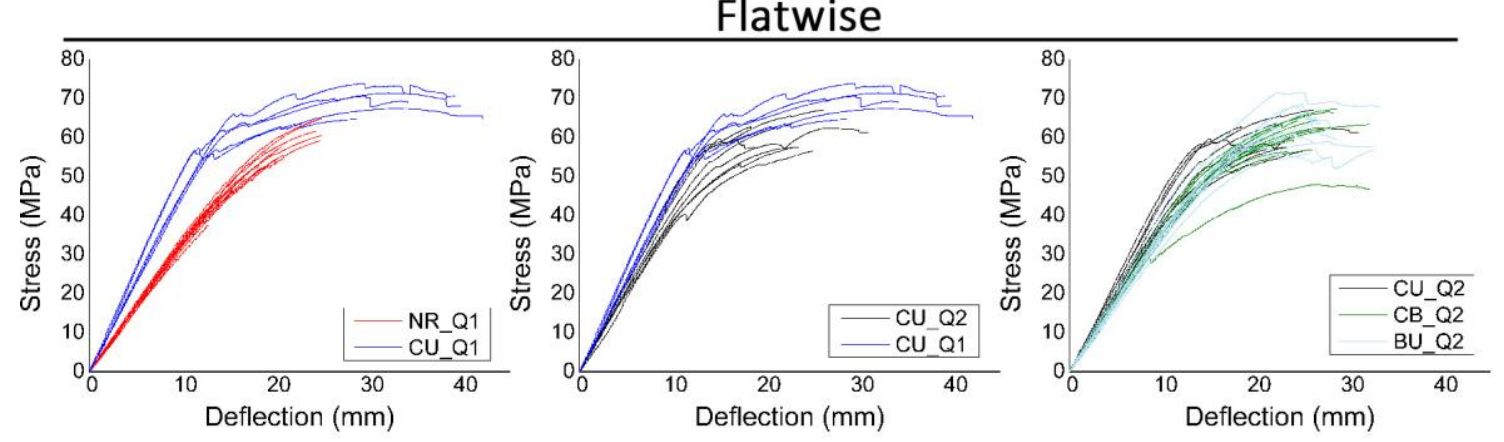

Edgewise
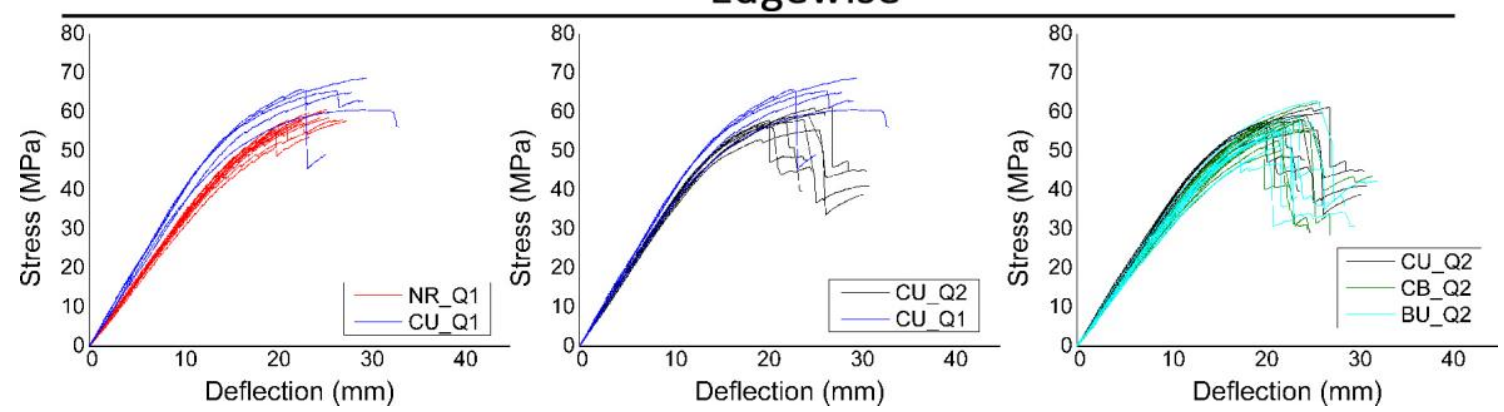

Figure 12. Stress versus global deflection for all the LVL poplar beams tested in flatwise and edgewise.

\begin{tabular}{ccccccc}
\hline \multirow{2}{*}{ Reinforcement/Quality } & \multicolumn{2}{c}{$\mathbf{M o E}_{\text {dyn }}(\mathrm{GPa}) \pm \mathbf{C O V}$} & \multicolumn{2}{c}{$\mathbf{M o E}_{\mathrm{m}, \mathrm{g}}(\mathrm{GPa}) \pm \mathrm{COV}$} & \multicolumn{2}{c}{$\begin{array}{c}\text { Max. Stress } \\
\text { (MPa) } \pm \text { COV }\end{array}$} \\
\cline { 2 - 7 } & FW & EW & FW & EW & FW & EW \\
\hline NR_Q1 & $9.4 \pm 4.1 \%$ & $9.5 \pm 2.6 \%$ & $8.9 \pm 4.6 \%$ & $8.6 \pm 3.3 \%$ & $58.1 \pm 12.9 \%$ & $59.9 \pm 4.2 \%$ \\
CU_Q1 & $13.9 \pm 11.0 \%$ & $11.3 \pm 4.8 \%$ & $12.7 \pm 7.2 \%$ & $10.5 \pm 5.6 \%$ & $72.1 \pm 5.0 \%$ & $67.7 \pm 4.4 \%$ \\
Var. respect NR_Q1 (\%) & 48.5 & 19.1 & 42.2 & 22.1 & 24.1 & 13.0 \\
\hline
\end{tabular}


Table 5. Main mechanical properties of the LVL poplar beams tested for Group I: Evaluation of the enhancement provided by reinforcement $\mathrm{CU}$.

Regarding Group I (NR/CU - Q1), it can be clearly observed that the CU_Q1 beams reached higher values for all the mechanical properties respecting to the nonreinforced ones, making especially relevant the enhancement for the case of elastic modulus of flatwise beams. The improvement of $\mathrm{MoE}_{\mathrm{dyn},} \mathrm{MoE}_{\mathrm{m}, \mathrm{g}}$ and maximum stress for flatwise beams was of $48.5 \%, 42.2 \%$ and $24.1 \%$, respectively, while for the case of edgewise ones, the improvement was of $19.1 \%, 22.1 \%$ and $13.0 \%$, respectively. Both enhancements in EW elastic moduli were fully in accordance with those obtained in the case of Douglas fir LVL (19.5\% and $20.4 \%$ for the $\mathrm{MoE}_{\mathrm{dyn}}$ and $\mathrm{MoE}_{\mathrm{m}, \mathrm{g}}$, respectively). However, the improvement in EW maximum bending stress was higher for Douglas fir LVL, $40.9 \%$ instead of $13 \%$, but the CU reinforced values were similar $(67.7 \mathrm{MPa}$ and 69.0 MPa for poplar and Douglas fir, respectively). Thus, the relative improvements of the same CU reinforcement were different, and this may be explained by different veneer qualities. Figure 12 shows a remarkable improvement in the ductility behavior for the CU_Q1 beams compared to the common brittle failure of NR beams. This ductile behavior can be explained by the ductile behavior of poplar under compressive stress, the LVL being compressed while the FRP resisted under the tensile stresses.

Table 6 summarizes the results obtained for the beams of Group II, comparing the same type of reinforcement for different qualities of the panel. The importance of considering veneer quality as a key parameter to evaluate the mechanical results is clearly demonstrated. In particular, the improvements of the $\mathrm{MOE}_{d y n}, \mathrm{MoE}_{\mathrm{m}, \mathrm{g}}$ and maximum stress for flatwise testing in the case of CU_Q1 beams were of $11.5 \%$, $14.6 \%$ and $12.3 \%$, respectively, while for the edgewise testing they were of $6.0 \%$, $14.6 \%$ and $10.5 \%$, respectively. As expected, reinforced flatwise beams achieved higher values than edgewise regardless of the quality of the panel. The improvement in ductility for both the FW and EW layouts (Figure 12) is evident when compared with non-reinforced beams, no matter the quality of the panel is.

\begin{tabular}{|c|c|c|c|c|c|c|}
\hline \multirow{2}{*}{$\begin{array}{l}\text { Reinforcement/Quali } \\
\text { ty }\end{array}$} & \multicolumn{2}{|c|}{$\mathrm{MoE}_{\text {dyn }}(\mathrm{GPa}) \pm \mathrm{COV}$} & \multicolumn{2}{|c|}{$\mathrm{MoE}_{\mathrm{m}, \mathrm{g}}(\mathrm{GPa}) \pm \mathrm{COV}$} & \multicolumn{2}{|c|}{$\begin{array}{l}\text { Max. Stress } \\
(\mathrm{MPa}) \pm \mathrm{COV}\end{array}$} \\
\hline & FW & EW & FW & EW & FW & EW \\
\hline CU_Q2 & $12.5 \pm 8.5 \%$ & $\begin{array}{c}10.7 \pm 2.4 \\
\%\end{array}$ & $\begin{array}{c}11.0 \pm 6.1 \\
\%\end{array}$ & $9.8 \pm 3.1 \%$ & $\begin{array}{c}63.2 \pm 5.8 \\
\%\end{array}$ & $\begin{array}{c}60.6 \pm 3.2 \\
\%\end{array}$ \\
\hline CU_Q1 & $\begin{array}{c}13.9 \pm 11.0 \\
\%\end{array}$ & $\begin{array}{c}11.3 \pm 4.8 \\
\%\end{array}$ & $\begin{array}{c}12.7 \pm 7.2 \\
\%\end{array}$ & $\begin{array}{c}10.5 \pm 5.6 \\
\%\end{array}$ & $\begin{array}{c}72.1 \pm 5.0 \\
\%\end{array}$ & $\begin{array}{c}67.7 \pm 4.4 \\
\%\end{array}$ \\
\hline $\begin{array}{c}\text { Var. respect CU_Q2 } \\
(\%)\end{array}$ & 11.5 & 6.0 & 14.6 & 6.9 & 12.3 & 10.5 \\
\hline
\end{tabular}

Table 6. Main mechanical properties of the LVL poplar beams tested for Group II: Evaluation of the influence of the panel quality.

\begin{tabular}{|c|c|c|c|c|c|c|}
\hline \multirow{2}{*}{$\begin{array}{l}\text { Reinforcement/Quali } \\
\text { ty }\end{array}$} & \multicolumn{2}{|c|}{$\mathrm{MoE}_{\text {dyn }}(\mathrm{GPa}) \pm \mathrm{COV}$} & \multicolumn{2}{|c|}{$\mathrm{MoE}_{\mathrm{m}, \mathrm{q}}(\mathrm{GPa}) \pm \mathrm{COV}$} & \multicolumn{2}{|c|}{ Max. Stress $(\mathrm{MPa}) \pm \mathrm{COV}$} \\
\hline & FW & EW & FW & EW & FW & EW \\
\hline CU_Q2 & $12.5 \pm 8.5 \%$ & $10.7 \pm 2.4 \%$ & $11.0 \pm 6.1 \%$ & $9.8 \pm 3.1 \%$ & $63.2 \pm 5.8 \%$ & $\begin{array}{c}60.6 \pm 3.2 \\
\%\end{array}$ \\
\hline CB_Q2 & $11.0 \pm 2.0 \%$ & $10.0 \pm 2.6 \%$ & $9.4 \pm 4.2 \%$ & $8.8 \pm 4.0 \%$ & $62.7 \pm 8.5 \%$ & $\begin{array}{c}58.9 \pm 5.3 \\
\%\end{array}$ \\
\hline BU_Q2 & $10.6 \pm 5.9 \%$ & $9.9 \pm 3.7 \%$ & $9.5 \pm 6.0 \%$ & $8.9 \pm 5.6 \%$ & $64.6 \pm 8.4 \%$ & $\begin{array}{c}57.6 \pm 6.1 \\
\%\end{array}$ \\
\hline
\end{tabular}


Table 7. Main mechanical properties of the LVL poplar beams tested for Group III: Comparison of the three types of FRPs.

Group III compares the three types of FRP, CU, CB and BU, in a low-quality panel (Q2). It can be observed that the beams reinforced with carbon unidirectional FRP reached the highest values of mechanical properties for both flatwise and edgewise testing, the latter always providing lower ones. Similar results were obtained for carbon bidirectional and basalt unidirectional reinforcements. This fact becomes relevant considering that the cost of the $\mathrm{BU}$ reinforcement is one third of $\mathrm{CB}$. The cost of the $\mathrm{CU}$ reinforcement is $70 \%$ and $400 \%$ higher than the CB and BU reinforcement, respectively. Comparing the elastic modulus of the CB reinforcement for LVL Douglas fir and poplar beams, an improvement respect to non-reinforced beams of the latter was obtained, which may be due to the fact that the FRP material was embedded. This behaviour can be associated with the fact that the external veneers when CB reinforcement is embedded help to reduce the transversal deformation of this type of fabric. Note that in all cases, $\mathrm{MoE}_{\mathrm{dyn},}, \mathrm{MoE}_{\mathrm{m}, \mathrm{g}}$ and maximum stress values were higher than those of the NR_Q1 beams. This translates directly into a greater use of wood as a base raw material, and therefore, of a better use of second quality wood characterized by a higher presence of knots, lower density and thus lower and more scattered mechanical properties. As Figure 12 shows, regardless of the type of FRP reinforcement, the beams show a ductile behavior, especially in the case of FW beams.

\section{Conclusions}

An evaluation of the bending properties of Douglas fir and poplar LVL beams reinforced with different fibers has been carried out, studying the effects of different variables as the veneers quality and orientation in the beam. A clear improvement provided by unidirectional carbon is demonstrated (up to $40 \%$ more in the elastic modulus for the flatwise layout and more than $20 \%$ of the maximum stress, for both types of wood). However, a modest enhancement of the mechanical properties was provided by the bidirectional carbon and the unidirectional basalt.

For the case of low quality Douglas fir LVL beams, placing the reinforcement at the external part of the beam, a clear enhancement of the main mechanical properties $\mathrm{MoE}_{\mathrm{dyn}}, \mathrm{MoE}_{\mathrm{m}, \mathrm{g}}$ and maximum bending stress was achieved when unidirectional carbon reinforcement was used $(19.5 \%, 20.4 \%$ and $40.9 \%$, respectively). On the opposite, bidirectional reinforcement only improves the maximum bending stress (16.4\%).

During the manufacturing process of the LVL poplar beams, the reinforcement was embedded, allowing it to be hidden from view. Furthermore, two quality of wood-panel manufacturing was analyized, Q1 and Q2 for high and low quality, respectively. The analysis was divided in 3 groups. For group I, Q1 panel, non-reinforced versus unidirectional carbon reinforced beams, a remarkable improvement of the mechanical properties was achieved in flatwise bending (48.5\%, 42.2\% and $22.1 \%$ for $\mathrm{MoE}_{\mathrm{dyn}}$, $\mathrm{MoE}_{\mathrm{m}, \mathrm{g}}$ and maximum stress, respectively). Comparing the edgewise tests from both species, results were in totally accordance, suggesting that these results can be transferable to other types of wood. Furthermore, the influence of the quality of the panel has been proven, comparing the same type of reinforcement for Q1 and Q2 panels: reinforced Q2 poplar LVL exhibited better mechanical properties than non reinforced Q1 LVL. This fact could lead to a better use of wood material and for example the upper parts of the tree (usually lower quality).

When comparing different types of reinforcements for low quality panels, as expected, the $\mathrm{CU}$ reinforced beams achieved the higher values, obtaining similar results for carbon bidirectional and basalt unidirectional. It is important to note that basalt fiber 
costs is $1 / 3$ of carbon fiber. Comparing the cost difference against mechanical properties enhancement, the application of additional layers using basalt fiber could lead in a better solution than a single CU layer at a lower cost. The additional manufacturing costs due to the application of reinforcements should also been evaluated. To evaluate that, a deep analysis is needed. A comparison between the dynamic modulus in flatwise and edgewise position for each beam has been carried out, remarking the enhancement of the reinforced beams in both positions. The relationship between $\mathrm{MoE}_{\mathrm{dyn}-\mathrm{FW}} / \mathrm{MoE}_{\mathrm{dyn}-\mathrm{Ew}}$ has been calculated, obtaining a value of 0.99 for the non-reinforced beams, meanwhile this value was of $1.22,1.20,1.10$ and 1.07 for CU_Q1, CU_Q2, CB_Q2 and BU_Q2 beams, respectively. The bidirectional carbon fiber reinforced beams provided an increase of the $\mathrm{MoE}_{\mathrm{dyn}}$ in both positions due to its braiding with a possible shear benefits. More studies are needed on this topic.

\section{Acknowledgments and funding sources}

Funding: This work has been possible thanks to financial support of the COMPOP_Timber project "Desarrollo de productos de ingeniería elaborados a base de tablones $\bar{y}$ chapas de chopo con inserciones de material compuesto para su uso en construcción", BIA2017-82650-R,

Acknowledgements to the region of Burgundy Franche-Comté, France Douglas, and Thebault Group. This work is a consequence of the postdoc stay carried out by Dr. Rescalvo at LaBoMaP.

\section{Contribution of the authors}

F.J.R.: majority of writing, majority of experimental work, experimental design, majority of data analysis and interpretation; R.D.: writing, experimental work and design; G.P.: supervision, writing, majority of experimental design, data analysis and interpretation; A.G.: main supervision, writing, experimental work and design, data analysis and interpretation; L.D.: writing, experimental design, data analysis and interpretation.

\section{Bibliography}

1. Jefree, M. Wood. Building the bioeconomy. 2019. www.CEI-BOIS.org

2. Rahayu, I.; Denaud, L.; Marchal, R.; Darmawan, W. Ten new poplar cultivars provide laminated veneer lumber for structural application. Ann. For. Sci. 2015, 72, 705-715. Doi: 10.1007/s13595-0140422-0

3. Laufenberg, T.L. Parallel-laminated veneer: processing and performance research review. Forest Prod J. 1983, 33, 21-28.

4. Burdurlu, E.; Kilic, M.; Ilce, A.C.; Uzunkavak, O. The effects of ply organization and loading direction on bending strength and modulus of elasticity in laminated veneer lumber (LVL) obtained from beech (Fagurs orientalis L.) and Lombardy poplar (Populus nigra L.). Constr. Build. Mater. 2007, 21, 17201725. Doi: 10.1016/j.conbuildmat.2005.05.002

5. Strickler, M.D.; Pellerin, R.F. Tension proof loading of finger joint for laminated beams. Forest Prod J. 1971, 21(2), 10-15.

6. Viguier, J.; Bourgeay, C.; Rohumaa, A.; Pot, G.; Denaud, L.; An innovative method based on grain angle measurement to sort veneer and predict mechanical properties of beech laminated veneer lumber. Constr Build Mat. 2018, 181, 146-155. Doi: 10.1016/j.conbuildmat.2018.06.050

7. Marx, C.M.; Moody, R.C. Effects of lumber width and tension laminated quality on the bending strength of four ply laminated beams. Forest Prod J. 1982, 32(1), 45-52. Doi: 10.1016/j.conbuildmat.2005.05.002

8. Youngquist, J.A.; Laufenberg, T.L.; Bryant, B.S. End jointing of laminated veneer lumber for structural use. Forest Prod J. 1984, 34(11-12), 25-32.

9. Wolf, R; Moody, R.C. Bending strength of vertically glued laminated beams. Forest Prod J. 1979, $30(6), 32-40$. 
10. Purba, C. Y. C.; Pot, G.; Viguier, J.; Ruelle, J.; Denaud, L. The influence of veneer thickness and knot proportion on the mechanical properties of laminated veneer lumber (LVL) made from secondary quality hardwood. Eur J Wood Wood Prod. 2019, 77 (3), 393-404. Doi: 10.1007/s00107-019-01400-3

11. Theakston, F. A feasibility study for strengthening timber beams with fiberglass. Can. Agric. Eng. 1965, 7, 17-19.

12. Biblis, E. Analysis of wood-fiberglass composite beams within and beyond the elastic region. FPJ 1965, 15, 81-88.

13. Laufenberg, T.L.; Rowlands, R.E.; Krueger, G.P. Economic feasibility of synthetic fiber reinforced laminated veneer lumber (LVL). Forest Prod J. 1984, 34(4), 15-22.

14. Tichy, R.J.; Bodig, G.J. Flexural properties of glued laminated lodgepole pine dimension lumber. Forest Prod J. 1978, 29(9), 52-64.

15. Shihong, L.; Benli, G.; Jiaqing, L. Experimental study on poplar LVL beams reinforced with CFRP sheets. Jiangsu Constr. 2007, 6. Doi: 10.15376/biores.8.4.4883-4898

16. Wei, P.; Wang, B.J.; Zhou, D.; Dai, C.;Wang, Q.; Huang, S. Mechanical properties of poplar laminated veneer lumber modified by carbon fiber reinforced polymer. Bioresources, 2013, 8(4), 4883-4898. Doi: 10.15376/biores.10.4.7455-7465

17. Gilfillan J.; Gilbert S.; Patrick G. The use of FRP composites in enhancing the structural behavior of timber beams. Journal of Reinforced Plastics Composites. 2003, 22(15), 1373-1388. Doi: $10.1177 / 073168403035583$

18. Hng, P.S.; Paridah; Chin, K.L. Bending properties of laminated veneer lumber produced from keruing (Dipterocarpus sp.) reinforced with low density wood species. Asian J Sci Res. 2010, 3(2), 118-125. Doi: 10.3923/ajsr.2010.118.125

19. Pengyi, Z.; Shijie, S.; Chunmei, M.A. Strengthening mechanical properties of glulam with basalt fiber. Adv Natural Sci. 2011, 4(2), 130-133. Doi: 10.3968/g4683

20. Solarov, R.; Glišić, M. Glulam beams reinforced with frp strips and their application in architecture. Spat. 2014, 1-6. Doi: 10.2298/SPAT1432001S

21. Ansell, M.P. Hybrid wood composites-integration of wood with other engineering materials. Wood composites. 2015, 54, 411-426. Doi: 10.1016/B978-1-78242-454-3.00016-0

22. Rescalvo, F.J.; Valverde-Palacios, I.; Suarez, E.; Gallego, A. Experimental and analytical analysis for bending load capacity of old timber beams with defects when reinforced with carbon fiber strips. Compos. Struct. 2018, 186, 29-38. Doi: 10.1016/j.compstruct.2017.11.078

23. Rescalvo, F.J.; Valverde-Palacios, I.; Suarez, E.; Gallego, A. Experimental comparison of different carbon fiber composites in reinforcement layouts for wooden beams of historical buildings. Materials 2017, 10, ID 1113. Doi: 10.3390/ma10101113

24. Raftery G.M.; Harte A.M.; Low-grade glued laminated timber reinforced with FRP plate. Composites: Part B 2011, 42, 724-735. Doi: 10.1016/j.compositesb.2011.01.029

25. Bekir, C. Flexural properties, bonding performance and splitting strength of LVL reinforced with woben glass fiber. Constr Build Mat. 2014, 51, 9-14. Doi: 10.1016/j.conbuildmat.2013.10.041

26. Brancheriau, L.; Bailleres, H. Natural vibration analysis of clear wooden beams: a theoretical review. Wood Sci Technol, 2002, 36, 347-365. Doi: 10.1007/s00226-002-0143-7

27. Cirad. Non-destructive testing of wood. 2020. https://www.picotech.com/library/application-note/nondestructive-testing-of-wood.

28. UNE-EN 408:2011+A1:2012. Timber structures - Structural timber and glued laminated timber Determination of some physical and mechanical properties 